\title{
PENGARUH KUALITAS PRODUK TERHADAP KEPUTUSAN PEMBELIAN KENDARAAN BERMOTOR YAMAHA MIO PADA CV. ROLYA MOTOR DI BANDAR LAMPUNG
}

\author{
Khairul Saleh $\left({ }^{1}\right)$, Sodirin ${ }^{2)}$ Tiar Mirnasari ${ }^{(3)}$ \\ Universitas Sang Bumi Ruwa Jurai \\ Email : khairul.saleh@fe.saburai.ac.id, sodirin@fe.saburai.ac.id.Tiarmirnasari2021@gmail..com
}

\begin{abstract}
Abstrak. Penelitian ini bertujuan untuk mengetahui apakah kualias produk berpengaruh terhadap keputusan pembelian kendaraan bermotor yamaha mio. Objek penelitian ini adala di CV Rolya Motor di Bandar Lampung. Jenis penelitian yang digunakan dalam penelitian ini adalah kuantitatif deskriptif dengan anlisis data menggunakan regresi linear sederhana. Metode pengumpulan data yang digunakan adalah data primer dan data skunder. Teknik pengumpuln data berupa kusioner, observasi, dan dokumentasi. Berdasarkan penelitian disimpulkan bahwasnnya kualitas produk betpengaruh terhadap keputusan pembelian.
\end{abstract}

Kata Kunci : Kualitas Produk, Keputusan pembelian

\begin{abstract}
This study aims to determine whether product quality has an effect on purchasing decisions for Yamaha Mio motor vehicles. The object of this research is CV Rolya Motor in Bandar Lampung. The type of research used in this research is descriptive quantitative with data analysis using simple linear regression. Data collection methods used are primary data and secondary data. Data collection techniques in the form of questionnaires, observations, and documentation. Based on Keyword research, product quality has an effect on purchasing decisions.
\end{abstract}

Keywords: Product Quality, Purchase Decision

\section{PENDAHULUAN}

Ketatnya persaingan dalam dunia usaha menuntut setiap perusahaan untuk mengambil langkah-langkah dan strategi yang tepat guna memenangkan persaingan dengan kompetitor demi menjaga eksistensi yang dimiliki perusahaan dan tentunya mempertahankan bahkan meningkatkan keuntungan atau profit yang dihasilkan. Tanpa strategi yang tepat perusahaan tidak akan dapat bertahan karena seiring waktu kompetitor akan terus muncul bersamaan dengan permintaan konsumen yang kian meningkat. Hal ini dihadapi oleh setiap perusahaan yang mencari laba dan tidak terkecuali industri sepeda motor. Saat ini, perkembangan jumlah penduduk yang cukup pesat serta beragamnya aktivitas kerja setiap orang memungkinkan segala aktivitas tersebut harus dilakukan secara cepat. Agar orang dapat melakukan pekerjaan secara cepat, dibutuhkan sarana pendukung, seperti sarana transportasi.

Perusahaan sepeda motor kini memiliki banyak dealer-dealer motor yang menjual sepeda motor dengan berbagai merek. Perusahaan sepeda motor dari berbagai merek tidak berhenti begitu saja untuk terus bersaing dalam menciptakan sepeda motor yang memiliki kualitas lebih baik dan lebih canggih. Bahkan perusahaan juga sering 
memberikan potongan harga dalam penjualan, potongan harga yang dilakukan perusahaan sering membuat pesaing bisnis penjualan sepeda motor baru semakin meningkat. Penggunaan sepeda motor di Indonesia sangat populer karena harganya yang relatif murah, terjangkau untuk sebagian besar kalangan dan penggunaan bahan bakarnya serta serta biaya operasionalnya cukup hemat.

Tabel 1.

Tabel Perbandingan Tingkat Penjualan selama Tahun 2018

\begin{tabular}{|c|c|c|c|c|c|c|}
\hline \multirow{2}{*}{$\mathrm{N}$} & \multirow{2}{*}{ Bulan } & \multicolumn{5}{|c|}{$\mathrm{M}$} \\
\hline & & Bea & Vari & Scop & Nma & $\mathrm{Mi}$ \\
\hline 1 & Januari & 8 & 7 & 9 & 7 & 1 \\
\hline 2 & Februari & $\overline{6}$ & $\overline{9}$ & 9 & 8 & $\hat{1}$ \\
\hline 3 & Maret & 1 & 1 & 1 & 1 & $\hat{1}$ \\
\hline 4 & April & 9 & $\overline{1}$ & 1 & 1 & $\hat{1}$ \\
\hline 5 & Mei & $\hat{1}$ & 8 & $\hat{1}$ & $\hat{1}$ & $\hat{1}$ \\
\hline 6 & Juni & 1 & $1^{-}$ & $i$ & 6 & $\hat{1}$ \\
\hline 7 & Juli & 1 & $i$ & $\hat{1}$ & $\hat{7}$ & 1 \\
\hline 8 & Agustus & 1 & 1 & 1 & 5 & 1 \\
\hline 9 & September & $\hat{1}$ & $\hat{1}$ & $\hat{1}$ & 1 & 1 \\
\hline 1 & Oktober & 1 & $i$ & 7 & 1 & 1 \\
\hline$\hat{1}$ & November & $\hat{1}$ & $i$ & 9 & 8 & 1 \\
\hline i & Desember & i & $i$ & $\overline{8}$ & $\overline{6}$ & 1 \\
\hline & Jumlah & 160 & 147 & 145 & 135 & $\hat{133}$ \\
\hline
\end{tabular}

Sumber : Dealer Honda Tunas Dwipa Matra 
Tabel 1. Yamaha Mio masuk sebagai motor terlaris di Indonesia. Yamaha Mio dapat peringkat ke lima dalam penjualan sepeda motor pada tahun 2018 dengan jumlah 1.335 unit yang disaingi oleh empat sepeda motor berupa Honda Beat dengan penjualan sebesar 1604 unit, Honda Vario series dengan penjualan sebesar 1473 unit dan Honda Scoopy dengan penjualan sebesar 1458 unit dan Yamaha Nmax dengan penjualan sebesar 1354.

Persaingan skuter matic yang semakin ketat membuat Yamaha terus terdorong untuk dapat memenuhi kebutuhan dan keinginan para konsumen yang semakin kompleks. Yamaha Mio pertama kali diperkenalkan di Indonesia pada tanggal 22 Juni 2009. Menurut data Asosiasi Industri Sepeda Motor Indonesia (AISI), penjualan Yamaha Mio sepanjang 2018 berhasil menembus angka 254.826 unit untuk seluruh Indonesia. Untuk tetap bertahan pada persaingan yang semakin ketat dalam dunia pemasaran di indonesia. Berikut adalah daftar penjualan sepeda motor Yamaha Mio di Bandar Lampung pada tahun 2018. Dari data pen.jualan motor di dapatkan hasil bahwa data penjualan sepeda motor

Yamaha Mio di daerah Bandar Lampung. Pada bulan Januari sampai Desember 2017, tercatat mampu menorehkan penjualan sebanyak 1.174 unit. Sedangkan pada tahun 2018 penjualan pada bulan Januari sampai November 2018 meningkat menjadi 1.335 unit.

Yamaha Mio merupakan motor produksi sepeda motor matik pertama yang menggunakan teknologi canggih dan memiliki kualitas produk yang baik maka keinginan konsumen terhadap suatu produk akan terpenuhi. Menurut Handoko
(2012 : 23) kualitas produk adalah suatu kondisi dari sebuah barang berdasarkan pada penilaian atas kesesuaiannya dengan standar ukur yang telah ditetapkan. Semakin sesuai standar yang ditetapkan maka akan dinilai produk tersebut semakin berkualitas. Kualitas produk juga merupakan hal penting yang harus diperhatikan oleh setiap perusahaan jika ingin produk yang dihasilkan dapat bersaing di pasar untuk memuaskan kebutuhan dan keinginan konsumen. Kualitas merupakan syarat utama diterimanya suatu produk di pasar. Suatu produk dikatakan berkualitas apabila produk tersebut mampu memenuhi harapan pelanggan. Menurut Kotler Philip (Dinawan 2010) Kualitas produk mempunyai delapan dimensi kualitas yaitu kinerja (performance), fitur (features), kehandalan (reliability), kesesuaian dengan spesifikasi (conformance to specifications), daya tahan (durability), kemampuan layanan (service ability), estetika (aesthetics), dan kualitas yang dirasakan (perceived quality).

Berdasarkan penelitian sebelumnya (Kusumawardani 2011) menunjukan membuktikan bahwa sikap konsumen yang dibangun berbasis kualitas pelayanan yang baik mampu mengarahkan dan pada akhirnya akan mendorong terbentuknya keputusan pembelian.

Kemudian penelitian lain oleh (Andika and Susanti 2018) Produk tidak berpengaruh signifikan terhadap Keputusan Pembelian konsumen Azzwars Parfum Lubeg Padang dan marketing mix berpengaruh terhadap keputusan pembelian.

Selanjutnya ditemukan bahwa (Akbar et al. 2019) penelitian ini menunjukkan bahwa promosi penjualan dan periklanan berpengaruh terhadap pemakaian kartu kredit. 
Berdasarkan latar belakang di atas peneliti terarik unuk meneliti tentang apakah kualias produk berpengaruh terhadap keputusan pembelian kendaraan bermotor yamaha mio di CV Rolya Motor di Bandar Lampung.

\section{METODE PENELITIAN}

Penelitian ini dilaksanakan pada CV. Rolya Motor di Lampung yang beralamat di Jalan RA. Kartini No. 126 Tanjungkarang Pusat, Kota Bandar Lampung.

Adapun metode pengumpulan data dalam penelitian ini diperoleh dari data primer dan data sekunder.

\section{Data Primer}

Data primer yaitu data yang dikumpulka dan diolah langsung dari objek penelitian, seperti catatan, agenda, dokumen, laporan tahunan dan sebagainya.

Data Sekunder

Merupakan data yang diperoleh melalui orang lain yang berhubungan dengan permasalahan yang dipecahkan. Data sekunder ini diperoleh melalui cara studi dokumenter yaitu mengumpulkan adn mempelajari brosur-brosur serta dokumendokumen, catatan-catatan dan arsip perusahaan.

Teknik pengumpulan data yang digunakan Observasi, wawancara, kusioner dan dokumentasi. Responden dalam penelitian iniadalah sebanyak 18 orang.

\section{Analisis Kualitatif}

Yaitu menganalisa permasalahan dengan cara membandingkan antara teori dengan permasalahan yang dihadapi oleh CV. Rolya Motor di Bandar Lampung, yaitu mengenai pembelian kendaraan bermotor.

\section{Analisis Kuantitatif \\ Uji Persamaan Linear Sederhana}

Dalam menganalisis secara kuantitatif penulis menggunakan rumus statistik yaitu rumus uji linear sederhana sebagai berikut :

$\mathbf{y}=\mathbf{a}+\mathbf{b x}+\mathbf{e}$

$\mathrm{y}=$ Kualitas Produk

$\mathrm{x}=$ Keputusan Pembelian

$\mathrm{e}=$ error

\section{HASIL DAN PEMBAHASAN}

\section{Analisis Kualitaif}

Uji kualitaif dilakukan dengan uji validitas dan uji reablitas hasilnya bahwa valid dan reliable.

\section{Analisis Kuantitatif}

Persamaan regresi antara variabel Kualitas Produk (X) terhadap variabel Keputusan Pembelian (Y) adalah $\mathrm{Y}=0,758+0,974 \mathrm{X}$ penjelasannya adalah :

$\mathrm{B} 0=0,758$ merupakan nilai konstanta atau yang dapat diartikan bahwa kualitas produk bernilai konstan, maka bila setiap terjadi peningkatan nilai pada variabel keputusan pembelian sebesar satu point, berakibat kualitas produk hanya akan meningkat sebesar $0,758 \%$.

$\mathrm{Bx}=, 974$ yang dapat dinyatakan bahwa setiap penambahan tanggapan responden mengenai kualitas produk, maka dapat 
diikuti oleh keputusan pembelian sebesar $97,0 \%$ atau setiap terjadi peningkatan nilai pada variabel keputusan pembelian sebesar

\section{Uji Determinitas Uji Determinasi $\left(\mathbf{R}^{2}\right)$}

Berdasarkan penelitian di dapatkan bahwa Koefisien Determinasi $=\mathrm{R}^{2}=$ $0,949^{2}=0,901=0,901 \times 100=90,1 \%$. Dapat disimpulkan bahwa variabel kualitas produk menjelaskan variasi perubahan terhadap variabel keputusan pembelian kendaraan bermotor yamaha Mio pada CV. Rolya Motor di Bandar Lampung sebesar 90,1\%, sedangkan sisanya dijelaskan oleh faktor lain yang tidak dikaji dalam penelitian ini

Berdasarkan hasil penelitian diperoleh kesimpulan; (1) hasil uji regresi linier sederhana adalah motivasi berpeb=ngaruh terhadap prestasi kerja karyawan, (2) hasil uji T sebagai berikut $t$ satu point, maka keputusan pembelian akan meningkat sebesar 0,974 point

hitung lebih besar dari $t$ tabel maka Ha diterima. Signifikasi variabel motivasi adalah 0.000 yang berarti probabilitas 0.000 , karena probabilitas kurang dari 0,05 maka $\mathrm{Ha}$ diterima. artinya motivasi berpengaruh positif terhadap Prestasi Kerja.

\section{Uji Hipotesis Perhitungan Pengaruh} Kualitas Produk (X) terhadap Keputusan Pembelian (Y)

Perhitungan pengaruh antara variabel Kualitas Produk (X) terhadap variabel Keputusan Pembelian (Y) kendaraan bermotor Yamaha Mio pada CV. Rolya Motor di Bandar Lampung menggunakan hasil perhitungan melalui program SPSS 21 untuk uji statistik adalah sebagai berikut:

Tabel

Uji Hipotesis Pengaruh Kualitas Produk terhadap Keputusan Pembelian

\begin{tabular}{|c|c|c|c|c|c|c|c|}
\hline \multirow[b]{2}{*}{ Model } & \multicolumn{2}{|c|}{$\begin{array}{c}\text { Unstandariz d } \\
\text { Coeficient } \\
\text { s }\end{array}$} & \multirow{2}{*}{$\begin{array}{l}\text { Standarize } \\
\mathrm{d} \\
\text { Coeficients } \\
\qquad \begin{array}{c}\text { Bet } \\
\text { a }\end{array}\end{array}$} & \multirow[b]{2}{*}{$t$} & \multirow[b]{2}{*}{$\begin{array}{l}\text { si } \\
\mathrm{g}\end{array}$} & \multicolumn{2}{|c|}{$\begin{array}{c}95 \% \\
\text { Confidence } \\
\text { Inerval for }\end{array}$} \\
\hline & B & $\begin{array}{l}\text { Std. } \\
\text { Error }\end{array}$ & & & & $\begin{array}{l}\text { Lower } \\
\text { Bound }\end{array}$ & $\begin{array}{l}\text { Upper } \\
\text { Bound }\end{array}$ \\
\hline 1 & $\begin{array}{l}.75 \\
8\end{array}$ & $\begin{array}{c}3.16 \\
7\end{array}$ & $a$ & $\begin{array}{c}.23 \\
9\end{array}$ & $\begin{array}{l}.81 \\
4\end{array}$ & $\begin{array}{c}.3 .83 \\
7\end{array}$ & $\begin{array}{l}4.14 \\
5\end{array}$ \\
\hline (volistan & $\begin{array}{l}.97 \\
4\end{array}$ & $\begin{array}{c}.08 \\
1\end{array}$ & 9 & $\begin{array}{c}12.06 \\
0\end{array}$ & $\begin{array}{l}.00 \\
0\end{array}$ & $\begin{array}{c}.89 \\
1\end{array}$ & $\begin{array}{l}1.08 \\
9\end{array}$ \\
\hline Kualitas & & & & & & & \\
\hline Produk & & & & & & & \\
\hline
\end{tabular}




\begin{abstract}
Berdasarkan hasil Uji $\mathrm{t}$ didapat nilai $\mathrm{t}$ hitung $=12,060$. Apabila dibandingkan dengan $\mathrm{t}$ tabel pada taraf signifikan 95\% yaitu 1,73 maka t hitung = $12,060>\mathrm{t}$ tabel $=1,73$ sehingga dapat disimpulkan bahwa : Ha yang menyatakan terdapat pengaruh antara variabel Kualitas Produk (X) terhadap Keputusan Pembelian (Y) dapat diterima. Jadi variabel Kualitas Produk (X) berpengaruh terhadap variabel Keputusan Pembelian (Y).
\end{abstract}

Sedangkan berdasarkan hasil penelitian, diperoleh koefisien determinasi kualitas produk terhadap keputusan pembelian adalah sebagai berikut : Apabila merujuk dari hasil pembahasan berkenaan dengan pengaruh antara kualitas produk dan keputusan pembelian kendaraan bermotor Yamaha Mio pada CV. Rolya Motor di Bandar Lampung dimana berdasarkan hasil Uji $\mathrm{t}$ didapat nilai $\mathrm{t}$ hitung $=12,060$ dan setelah dibandingkan dengan $\mathrm{t}$ tabel pada taraf signifikan $95 \%$ yaitu 1,73, maka $\mathrm{t}$ hitung $=12,060>\mathrm{t}$ tabel $=1,73$ sehingga dapat disimpulkan bahwa: Ha yang menyatakan terdapat pengaruh antara variabel kualitas produk (X) terhadap keputusan pembelian (Y) dapat diterima. Jadi variabel kualitas produk (X) berpengaruh terhadap keputusan pembelian (Y).

Menurut hemat penulis, besarnya nilai $\mathrm{t}$ hitung $=12,060$ adalah karena kualitas produk ini terkesan lemah dan kalaupun ada pengaruh kualitas produk terhadap keputusan pembelian baru menampakkan peningkatan. Hal ini dibuktikan dengan perhitungan pada Koefisien Determinasi $=\mathrm{R} 2=0,9492=$ $0,901=0,901 \times 100=90,1 \%$. Dapat disimpulkan bahwa variabel keputusan pembelian menjelaskan variasi perubahan terhadap variabel kualitas produk sebesar $90,1 \%$, dan persamaan regresi antara variabel kualitas produk (X) terhadap variabel keputusan pembelian $(\mathrm{Y})$ adalah $\mathrm{Y}=$ $0,758+0,974 \mathrm{X}$ penjelasannya adalah $:$ bo $=$ 0,758 merupakan nilai konstanta atau yang dapat diartikan bahwa promosi bernilai konstan, maka bila setiap terjadi peningkatan nilai pada variabel kualitas produk sebesar satu point, berakibat keputusan pembelian hanya akan meningkat sebesar $0,758 \%$. Bx = 0,974 yang dapat dinyatakan bahwa setiap penambahan tanggapan responden mengenai kualitas produk, maka dapat diikuti oleh keputusan pembelian sebesar satu point, maka keputusan pembelian akan meningkat sebesar 0,974 point, artinya kualitas produk akan berjalan baik jika keputusan pembelian baik dan ini akan meningkatkan point sebesar 0,974 .

Bila kualitas produk baik, maka setidaknya keputusan pembelian kendaraan bermotor Yamaha Mio pada CV. Rolya Motor di Bandar Lampung dapat berjalan dengan baik

\section{KESIMPULAN}

Berdasarkan penelitian didapatkan hasil bahwa Berdasarkan hasil Uji t didapat nilai $\mathrm{t}$ hitung $=12,060$ dan setelah dibandingkan dengan $\mathrm{t}$ tabel pada taraf signifikan $95 \%$ yaitu 1,73 , maka $\mathrm{t}$ hitung = $12,060>\mathrm{t}$ tabel $=1,73$ sehingga dapat disimpulkan bahwa : Ha yang menyatakan terdapat pengaruh antara variabel Kualitas Produk (X) terhadap Keputusan Pembelian (Y) dapat diterima. Jadi variabel Kualitas Produk (X) berpengaruh terhadap variabel Keputusan Pembelian (Y)

Kemudian pada persamaan regresi antara variabel Kualitas Produk (X) terhadap variabel Keputusan Pembelian (Y) 
adalah $\mathrm{Y}=0,758+0,974 \mathrm{X}$ penjelasannya adalah : bo $=0,758$ merupakan nilai konstanta atau yang dapat diartikan bahwa Kualitas Produk bernilai konstan sebesar satu point, berakibat keputusan pembelian akan meningkat sebesar $0,758 \%$. $\mathrm{Bx}=0,974$ yang dapat dinyatakan bahwa setiap penambahan tanggapan responden mengenai Kualitas Produk, maka dapat diikuti oleh keputusan pembelian sebesar $97,0 \%$ atau setiap terjadi peningkatan nilai pada variabel Kualitas Produk sebesar satu point, maka keputusan pembelian akan meningkat sebesar 0,974 point.

Dengan demikian disimpulkan bahwa Kualitas Produk berpengaruh Terhadap Keputusan Pembelian Kendaraan Bermotor Yamaha Mio Pada CV. Rolya Motor Di Bandar Lampung

\section{Saran}

Berdasarkan kesimpulan yang telah dikemukakan diatas maka, maka penulis dapat memberikan saran sebagai berikut :

- Hendaknya kualitas produk yang ditawarkan oleh CV. Rolya Motor khusus kendaraan bermotor Yamaha Mio semakin baik lagi.

- Hendaknya pihak CV. Rolya Motor dapat memberikan pelayanan yang maksimal sehingga keputusan pembelian kendaraan bermotor Yamaha Mio akan semakin meningkat setiap tahunnya

- Untuk peneliti selanjutnya diharapkan untuk meneliti lebih lanjut.

\section{SDAFTAR PUSTAKA}

Akbar, Asmarullah, Zakaria Wahab, A. Widad, and Syamsurijal Ak. 2019. "ANALISIS PENGARUH PROMOSI PENJUALAN DAN PERIKLANAN TERHADAP PEMAKAIAN KARTU KREDIT BANK MANDIRI DI KOTA PALEMBANG." JURNAL MANAJEMEN DAN BISNIS SRIWIJAYA 17(1):17-30. doi: 10.29259/jmbs.v17i1.9030.

Arikunto, S., 2006, Prosedur Penelitian: Suatu pendekatan Praktik. Jakarta, Rineka Cipta.

Andika, Alfanda, and Febsri Susanti. 2018. PENGARUH MARKETING MIX TERHADAP KEPUTUSAN PEMBELIAN PARFUM DI AZZWARS PARFUM LUBEG PADANG. preprint. INA-Rxiv.

Dinawan, Muhammad Rhendria. 2010. "ANALISIS FAKTOR - FAKTOR YANG MEMPENGARUHI KEPUTUSAN PEMBELIAN (Studi Kasus Pada Konsumen Yamaha Mio PT Harpindo Jaya Semarang)." JURNAL SAINS PEMASARAN INDONESIA Volume IX, No. 3.

Kusumawardani, Dyah Ayu. 2011. "STUDI MENGENAI KEPUTUSAN PEMBELIAN JASA WEDDING AND EVENT ORGANIZER." Universitas Diponegoro 52. 
Khairul Saleh: Pengaruh Kualitas Produk Terhadap Keputusan Pembelian Kendaraan Bermotor Yamaha Mio Pada CV. Rolya Motor Di Bandar Lampung

Siagian, Sondang P. 2002. Manajemen Sumber Daya Manusia. Jakarta: PT Bumi Aksara

Sugiyono.2007.Metode Penelitian pedidikan pendekatan kuantitatif, kualitatif, dan R\&D.Bandung: Alfabeta. 